\title{
Voluntariado e o ensino de português língua de acolhimento: fazer o bem atrelado à ação profissional
}

\author{
Volunteer Work and the Teaching of Portuguese as a Host \\ Language: Wills to do Good Tied to Professional Action
}

\author{
María Aparecida Neves da Silva \\ Universidade de Brasilia, Brasil \\ e-mail: cidinhateacher1@gmail.com \\ María Luand Bezerra Campelo \\ Universidade de Brasilia, Brasil
}

Recibido: 30/11/2020

Aprobado: 24/05/2021

\begin{abstract}
RESUMO
Tendo em vista a importância do trabalho voluntário em nossa sociedade, considerando as contribuições que ações sem fins lucrativos produzem nos campos sociais, culturais e econômicos, pensou-se em um trabalho que oportunizasse o olhar do agente voluntário sobre suas escolhas, práticas e aspirações no ato de ensinar a Língua Portuguesa numa perspectiva do acolhimento (doravante PLAc). Desta forma, este artigo tem como objetivo analisar as motivações e opiniões de um grupo de 7 professores voluntários, que atuam em 3 projetos sociais, ofertando o ensino de Português gratuito para imigrantes e refugiados em Brasília - DF.
\end{abstract}

Palavras-chave: Voluntariado- Português Língua de Acolhimento- Ação Profissional.

\begin{abstract}
In view of the importance of the volunteer work in our society, considering the contributions of these non-profit actions produce on the social, cultural and economic areas, it was thought in a research aiming to provide the perspective of the volunteer about his/her choices, practices and aspiration on the act of teaching the Portuguese language as a host language (also known as PLAc). In this way, this paper has as it goal analyze the motivations and opinions of a group of 7 volunteer teacher, collaborators of 3 social projects, offering the free teaching of Portuguese for immigrants and refugees living in Brasília - DF.
\end{abstract}

Keywords: Volunteer Work- Portuguese as a Host Language- Professional Action.

\section{CONSIDERAÇÕES INICIAIS}

Partindo do pressuposto de que o trabalho voluntário é toda e qualquer atividade que uma pessoa ou grupo presta à comunidade, sem com isso buscar receber algum valor monetário, percebe-se que o voluntariado se torna uma prática que possibilita o fortalecimento dos laços sociais nos mais variados contextos de uma coletividade, como explana Cohen (1964) no excerto a seguir:

A pessoa que, por sua livre vontade, decide trabalhar em benefício de sua comunidade está na realidade dizendo: "Tenho dons e aptidões que são necessários; sou uma pessoa que aceita uma responsabilidade, não porque ela me é imposta, mas sim porque desejo 
ser útil. Meu direito de assim proceder é um símbolo de minha dignidade pessoal e meu valor" [...] A experiência do voluntário deve-lhe oferecer, além do sentimento de sentir-se útil como um indivíduo, a oportunidade de participar de modo significativo no programa geral e de intensificar o senso de responsabilidade social. (Cohen, 1964, p. 58)

Desta forma, pensa-se o ser voluntário como aquele/aquela que possui uma responsabilidade social primordialmente ligada a uma ação que levará a uma transformação. Assim, esse agente é capaz de contribuir no atendimento das necessidades comunitárias a partir de sua dedicação social.

Focando em práticas voluntárias para imigrantes e refugiados, a Organização das Nações Unidas", pontua que estas ações são fundamentais para que as "comunidades de acolhimento estejam prontas para aceitar pessoas deslocadas e lhes fornecer assistência de emergência e humanitária”. Desta forma, movimentos de voluntariado serão capazes de criar redes de segurança capazes de enfrentar crises e promover a inserção de imigrantes e refugiados na sociedade.

À vista disso, como se identifica e se percebe o professor voluntário de Português Língua de Acolhimento (PLAc) para imigrantes e refugiados? Considerando o fato de que motivação é algo complexo, individual e social (Cohen, 1964), focamos esta pesquisa em uma análise interpretativista das percepções de 7 professores voluntários que atuam no ensino de Português para estrangeiros em 3 projetos sociais voltados para atender as necessidades linguísticas deste público específico em Brasília, no Distrito Federal.

Esta pesquisa torna-se relevante uma vez que busca promover a compreensão do tema voluntariado no âmbito do ensino de línguas e num contexto de migração e refúgio. Desta forma, é possível contribuir para a organização de ações e grupos de apoio que possuem um objetivo comum: exercer a cidadania e solidariedade através da prática docente voluntária.

\section{O QUE DEFINE O VOLUNTARIADO?}

A ação voluntária apresenta-se como um "comportamento voltado para o social, de curto ou longo prazo, planejado, que beneficia pessoas desconhecidas e acontece em um ambiente organizacional" (Penner, 2002, p. 448). É uma oportunidade que diferentes indivíduos veem para trocar experiências, desenvolver um laço comunitário, doando tempo e esforço para contribuir com a solução de problemas sociais. $\mathrm{O}$ voluntariado é uma prática que está compreendida e resguardada em nossa Constituição, sendo também entendida como:

Art. $1^{\circ}$ Considera-se serviço voluntário, para os fins desta Lei, a atividade não remunerada, prestada por pessoa física a entidade pública de qualquer natureza, ou a instituição privada de fins não lucrativos, que tenha objetivos cívicos, culturais, educacionais, científicos, recreativos ou de assistência social, inclusive mutualidade.

Art. $2^{\circ} \mathrm{O}$ serviço voluntário será exercido mediante a celebração do termo de adesão entre a entidade, pública ou privada, e o prestador do serviço voluntário, dele devendo constar o objetivo e as condições de seu exercício.

Art. $3^{\circ} \mathrm{O}$ prestador do serviço voluntário poderá ser ressarcido pelas despesas que comprovadamente realizar no desempenho das atividades voluntárias. (BRASIL, 1998)

Desta forma, qualquer pessoa pode procurar algo que se encaixe com suas aptidões e interesses, sem estar diretamente relacionado com idade ou profissão, pois como bem pontua a Organização das Nações Unidas, o voluntário é o indivíduo que "devido ao seu interesse pessoal e ao seu espírito cívico, dedica parte de seu tempo, sem remuneração alguma, a diversas formas de atividades, organizadas ou não, de bem-estar social ou outros campos...". Assim, 
percebe-se que a importância dessa prática impacta tanto quem atua, quanto quem recebe tal ação.

Normalmente, ONGs, instituições religiosas, Universidade, escolas e empresas (tanto públicas quanto privadas) promovem ações voluntárias. Atualmente, observa-se uma relação próxima entre sociedade civil e o Estado para a promoção do voluntariado. Perceber e valorizar essa proximidade entre setores sociais, possibilita uma ação coletiva e complexa que estimula práticas pensando no bem para o outro, pois, como aponta Camargos (2008):

Com efeito, o elemento essencial do trabalho voluntário é o fato de ser prestado de forma gratuita e em comunhão com os interesses entre o trabalhador e a entidade que se aproveita de tal trabalho. Ao contrário, ambos têm os mesmos interesses naquela atividade e unem esforços para atingir os mesmos objetivos sociais. (Camargos, 2008, p. 67)

Entretanto, é importante salientar que o serviço voluntário ajuda no desenvolvimento pessoal do indivíduo que se propõe a atuar em determinados projetos, mas que, antes de iniciar qualquer atividade de cunho comunitário, o mesmo necessita saber de suas atribuições, como bem pontua o Manual de Procedimentos e Gestão do Voluntário, produzido pelo Serviço Social do Comércio (SESC) ao elencar que o voluntário deve:

- Desempenhar uma tarefa que o valorize e seja um desafio para ampliar habilidades ou desenvolver outras;

- Obter uma descrição clara de suas tarefas e responsabilidades;

- Participar das decisões com relação ao seu trabalho;

- Contar com os recursos indispensáveis para o trabalho voluntário;

- Receber capacitação e supervisão para melhorar o desempenho de sua tarefa, assim como a informação completa sobre a tarefa que deve desenvolver.

- Respeito aos termos acordados quanto à sua dedicação, tempo doado etc. e não ser desrespeitado na disponibilidade assumida;

- Receber reconhecimento e estímulo;

- Ter oportunidades para o melhor aproveitamento de suas capacidades, recebendo tarefas e responsabilidades de acordo com os seus conhecimentos, experiência e interesse. (SESC, 2007, p. 16)

Durante o exercício do trabalho voluntário, é possível perceber motivações, opiniões e troca de ideias que revelam a identidade do agente voluntário em seu meio organizacional. Sendo assim, como este voluntário se vê? Como ele se percebe atuante dentro de suas próprias práticas sociais? Em destaque para esta pesquisa, como um voluntário que se dedica ao ensino de seu próprio idioma para imigrantes e refugiados se percebe como agente transformador de um contexto social?

\section{ENSINO DE PORTUGUÊS LÍNGUA DE ACOLHIMENTO E A PRÁtICA VOLUNTÁRIA}

De acordo com o CONARE ${ }^{2}$ o Brasil representa atualmente o destino de imigrantes e refugiados oriundos de mais de 79 países. Dentre essas nacionalidades, encontram-se sírios, árabes, venezuelanos, congoleses, angolanos, nigerianos, dentre outras nacionalidades provenientes de várias regiões da África. Mais expressiva ainda foi a chegada de haitianos ao Brasil em 2010, sendo que de acordo com Amado (2016) esses imigrantes vieram ao Brasil devido à crise humanitária sofrida em seu país, lugar assolado por inúmeros desastres naturais, 
tendo como consequência a crise econômica e a falta de auxílio social, fazendo com que, motivados por melhorias de vida, muitos viessem ao Brasil em busca de refúgio.

Essas migrações são denominadas migrações de crise, como relatam Lopes e Diniz (2018). Segundo os supracitados autores, apesar de o Governo Federal apresentar iniciativas positivas, como é o caso da nova lei de Migração e Refúgios no 13.445/2017, ainda estamos longe de atendermos a todas as demandas que essas pessoas necessitam. Aos haitianos foi concedido um visto humanitário, ação estratégica para minimizar a problematização que o status de refúgio ocasionaria, uma vez que eles não se enquadram em tal denominação (Lopez, \& Diniz, 2018). Sobre esse assunto Amado (2016) acrescenta que:

O Brasil tem recebido haitianos desde 2010, quando um terremoto devastou o país caribenho. Em 2015, estima-se só em São Paulo cerca de 30 haitianos chegam por dia. Mas ainda que venham com pouquíssimos recursos os haitianos não podem solicitar a condição de refúgio por sua situação não atender ao quesito de perseguição. (Amado, 2016, p. 31)

A autora ainda afirma que a acolhida e inserção social de imigrantes e refugiados em situação de vulnerabilidade social muitas vezes fica a cargo da sociedade civil, e aqui encaixamos os agentes voluntários, sendo que esta parcela da sociedade civil busca, de forma voluntária, suprir algumas das várias demandas desses imigrantes e refugiados (Lopez, \& Diniz, 2018).

Dentre as lacunas estatais acerca das necessidades dessas pessoas está a oferta do ensino da língua majoritária nacional, que em nosso caso seria voltado para a oferta do ensino da língua portuguesa. Amado (2016, p. 32) relata que o ensino de Português "não é prioridade nas agendas governamentais das esferas federais, estaduais e nem municipais", desta forma, essa modalidade de ensino permanece a cargo de organizações não governamentais, projetos de extensão em universidades ou instituições religiosas.

Notadamente, há cursos pagos de Português para estrangeiros em instituições privadas de ensino, entretanto, nem todos os imigrantes possuem condições financeiras para arcarem com os custos que os referidos cursos apresentam (Lopez, \& Diniz, 2018), permanecendo, assim, algo inacessível para os estrangeiros que chegam ao país em situação de vulnerabilidade.

Desta maneira, há no país a oferta de cursos de Português voltados para a perspectiva do acolhimento desses imigrantes e refugiados. O termo "língua de acolhimento' foi inicialmente utilizado em Portugal por Ançã (2006), sendo que este país, assim como o Brasil, apresenta uma trajetória de acolhimento à imigrantes. Para Ançã, associações sem fins lucrativos e membros da sociedade civil desempenham papel de grande relevância e importância quanto à recepção destes imigrantes.

Dentre as atribuições de acolhimento ofertado por estas organizações, estava também a oferta voluntária do ensino de português para estrangeiros, proporcionando, em um primeiro momento, o ensino da língua oficial do país de uma forma que estas pessoas pudessem aprender o idioma para o uso rápido, seja buscando uma moradia, um atendimento hospitalar, um emprego e afins. Para a autora, denominar a língua de acolhimento tomou o significado literal que a palavra acolhimento remete, ou seja, acolhida, porto seguro, forte e refúgio ${ }^{3}$.

No Brasil, a perspectiva de acolhimento para o ensino de português tem sido utilizada na promoção de cursos de Português para imigrantes e refugiados em situação de vulnerabilidade a partir de ações voluntárias, que buscam, por meio do ensino da língua, promover uma relação positiva destes estrangeiros com a língua anfitriã, como afirmam Barbosa e São Bernardo (2017) no verbete publicado no Dicionário Crítico de Imigração e Refúgio: 
Nessa perspectiva, língua de acolhimento propõe uma revisão sobre o papel e a formação do(a) professor(a) que atua nesse contexto, pois ele(a) pode: $i$ ) amenizar o conflito inicial entre aprendente e língua; e ii) estabelecer as condições necessárias para que esse aprendente comece a vê-la e a interpretá-la como elemento de mediação entre ele(a) e a sociedade anfitriã. Desse modo, o(a) professor(a), o planejamento e o material didático constituem elementos-chave nesse processo de ensino-aprendizagem. (Barbosa, \& São Bernardo, 2017, p. 436)

Levando em consideração a situação de tensão que esses imigrantes e refugiados enfrentam ao chegarem ao país, este conflito linguístico é previsível (Barbosa, \& São Bernardo, 2017). É previsível também o "sentimento de rejeição e descaso no que se refere ao aprendizado do idioma majoritário de um país que não escolheram viver e que talvez nele não pretendem permanecer" (Barbosa, \& São Bernardo, 2017, p. 436). Assim, o professor voluntário que se dedica à ação de ensinar o idioma numa perspectiva de acolhimento, se vê diante de desafios, sentimentos múltiplos e da responsabilidade de buscar promover a inserção destes indivíduos em sociedade a partir de suas práticas profissionais.

\section{FAZER O BEM ATRELADO À AÇÃO PROFISSIONAL}

A importância do trabalho voluntário, tanto numa perspectiva social quanto econômica, se mostra intrinsicamente atrelada a motivações, desejos e ideais de um indivíduo ou grupo perante uma determinada comunidade. Quando uma pessoa se dispõe a procurar projetos e/ou ações voluntárias e se propõe a dedicar tempo e esforço em prol de uma causa, ela está procurando não só dar, mas também receber algo em troca, como afirma Cohen (1964) ao dizer que:

Todos nós sabemos que cada um tem suas motivações para fazer uma determinada tarefa. Sem motivações pessoais, sem necessidades pessoais e sem impulsos pessoais, nós não disporíamos de voluntários para qualquer programa. É importante reconhecer que essas necessidades são naturais e que todos nós precisamos dar vazão a elas. (Cohen, 1964, p. 193)

Sabe-se também que quando há o engajamento em práticas voluntárias, se está ciente de que não se tem uma compensação financeira, mas a participação do agente voluntário se mostra especial, justamente por esta peculiaridade: dedicar-se ao outro para fazer o bem. Desta maneira, independentemente das motivações (que são complexas e subjetivas), as recompensas imateriais são compensadoras, como Cohen (1964) acrescenta:

Algumas pessoas tomam parte no trabalho da comunidade por desejo consciente, outras por tradição de família, algumas por associação de circunstâncias. Talvez as razões para se iniciar sejam obscuras e não revelem uma intenção premeditada, mas os motivos para se continuar, depois de dada a partida, vão-se tornando cada vez mais claros à proporção que a pessoa participa do trabalho. As satisfações obtidas são das mais variadas espécies e os sentimentos de que se conseguiu algo são reais e compensadores. (Cohen, 1964, p. 93)

Prosseguindo com esta perspectiva de motivações, os pesquisadores Anheier e Salamon (1999) observaram 3 razões que podem influenciar os indivíduos a praticarem ações voluntárias, estas que são: instrumentais, altruístas e de obrigação. Nesse sentido, as razões instrumentais indicam a vontade de adquirir novas habilidades e experiências, o que se relaciona com uma satisfação pessoal. As razões altruísticas estão atreladas ao sentimento de 
solidariedade com o outro e crescimento pessoal e por último as razões de obrigação, que estão relacionados ao sentimento de dever moral, e também religioso para com a comunidade onde a pessoa que atua como voluntário se encontra.

Uma outra pesquisa desenvolvida por Clary, Snyder e Ridge (1992) apresenta 30 razões prováveis pelas quais pessoas, de um modo geral, se dedicam ao voluntariado. Destacamos, a seguir, os 6 motivos principais:

1) Motivo Social: Objetivando criar e expandir relações com pessoas diversas;

2) Valores: Preocupação com assuntos e/ou questões humanitárias;

3) Carreira: Trabalhar como voluntário pode agregar experiência profissional para o indivíduo e impulsionar o currículo do mesmo;

4) Aprendizagem: Oportunidade de desenvolver novas habilidades e internalizar novos conhecimentos;

5) Proteção: Preenchimento de tempo livre e busca por atividades que façam a pessoa se sentir útil;

6) Estima: Sentimento de pertencimento e importância, uma valorização pessoal pela atividade que exerce;

À vista disso, objetivando uma construção social e cidadã, a sociedade civil se engaja em papeis sociais com foco no voluntariado para atingir um fim específico, e aqui englobamos afinidade ideológica, religiosa, altruística, profissional e pessoal. Pensando no ambiente universitário, é possível identificar a presença de estudantes e profissionais da área educacional que utilizam projetos e atividades sociais para colocarem em prática teorias adquiridas em sala de aula. O engajamento destas pessoas demonstra que ações profissionais estão interligadas com ações sociais, ou seja, o voluntariado também pode ser um caminho para o processo de desenvolvimento de uma carreira.

\section{PROCEDIMENTOS METODOLÓGICOS}

Para o desenvolvimento desta pesquisa, utilizamos as informações cedidas por um grupo de 7 professores voluntários que atuam em 3 projetos sociais, sendo que 2 são vinculados à Universidade de Brasília. Todos os projetos aqui citados têm como objetivo promover o ensino de português gratuito para estrangeiros.

A primeira iniciativa se chama Projeto Interdisciplinaridade e Inserção de Imigrantes e Refugiados à Cultura Brasileira e ao Português Brasileiro ${ }^{4}$, coordenado pelo professor Doutor Umberto Euzebio, com o ensino voluntário de Português para estrangeiros residindo na cidade de São Sebastião (Distrito Federal). Os professores envolvidos neste projeto são alunos da universidade, sendo que o público alvo são venezuelanos e haitianos, mas também há a participação de alunos provenientes de outros países.

A segunda iniciativa se chama PROACOLHER ${ }^{5}$, que promove o ensino de Português língua de acolhimento para imigrantes e refugiados em situação de vulnerabilidade. Tal projeto é coordenado pela Professora Doutora Lúcia Maria de Assunção Barbosa e acontece tanto no ambiente da Universidade de Brasília quanto na cidade satélite Ceilândia, atendendo a inúmeros estrangeiros vindos de países como Síria, Haiti, Congo, Peru, Venezuela, Togo, Benim, dentre outros. Os professores que atuam neste trabalho são estudantes da universidade (graduandos, mestrandos e doutorandos) além de colaboradores externos. Este projeto também conta com o apoio Do Alto Comissariado das Nações Unidas para Imigrantes e Refugiados (ACNUR).

A terceira iniciativa se chama Aldeias Infantis SOS Brasil ${ }^{6}$, que é uma organização humanitária que tem como objetivo oferecer subsídios para que imigrantes e refugiados possuam meios para se estabelecerem nos países em que se encontram. Dentre as muitas atividades ofertadas, há o voluntariado para o ensino de Português para estrangeiros. 
Desta forma, esta é uma pesquisa qualitativa-interpretativista que objetiva compreender as motivações e perspectivas sociais e profissionais de 7 professores voluntários no ensino de PLAc. De acordo com Burrel e Morgan (1979), uma análise interpretativista tem como princípio compreender a experiência subjetiva das ações de indivíduos por meio de um estudo que possibilite a compreensão de vivências sociais destas pessoas.

Para Rey (2005), os indivíduos não estão deslocados de seus contextos sociais, pelo contrário, são produtos do meio em que se encontram. Assim, ambientes de trabalho, ambientes familiares e afins acarretam subjetividades, que produzem sentidos (Morgan, Frost, \& Pondy, 1983). Para tal, procuramos analisar a subjetividade dos voluntários que participaram desta pesquisa a partir de respostas cedidas pelos mesmos, por meio de um questionário, utilizando a plataforma Formulário Google.

O questionário serviu como um meio de coleta de dados a respeito do ponto de vista dos participantes à questão proposta, ou seja, suas motivações e percepções acerca da prática voluntária docente do Português como Língua de Acolhimento para imigrantes e refugiados em situação de vulnerabilidade e suas vivências nesta prática não remunerada. No formulário, os participantes escolheram pseudônimos, salvaguardando suas identidades.

\section{ANÁLISE DE DADOS}

Para a coleta de dados desta pesquisa, utilizamos as respostas provenientes de um grupo de 7 professores voluntários que atuam/atuaram em 3 projetos sociais, com o objetivo de oferecer o ensino da língua portuguesa para imigrantes e refugiados.

Identificamos que os participantes se caracterizam como um grupo de jovens voluntários, com uma faixa etária entre 22 e 44 anos, sendo que prevalece o gênero feminino atuante no trabalho voluntário. Dentre os voluntários, 6 possuem formação em nível superior e 1 está terminando a graduação. Apenas 1 dos 7 voluntários teve experiência com trabalho remunerado, mostrando que este grupo, em específico, está utilizando estes espaços de ações de promoções sociais para terem suas primeiras experiências profissionais, como é possível ver na Tabela 1.

Tabela 1. Perfil dos participantes

\begin{tabular}{|c|c|c|c|c|}
\hline Participante & Idade & Formação Acadêmica & $\begin{array}{l}\text { Tempo de trabalho } \\
\text { com carteira assinada }\end{array}$ & $\begin{array}{l}\text { Tempo de trabalho } \\
\text { voluntário }\end{array}$ \\
\hline Ana & 27 anos & Mestrado em Linguística & Nenhum & 6 anos \\
\hline Maria & 22 anos & Graduação Letras-Francês & Nenhum & 2 anos e 6 meses \\
\hline Bruno & 25 anos & Professor de Inglês & 1 ano e 6 meses & 1ano \\
\hline Babel & 25 anos & Professor de Francês & 1 ano & 1 ano \\
\hline Divina & 44 anos & $\begin{array}{l}\text { Graduação } \\
\text { (mas não especificou o curso) }\end{array}$ & Nenhum & 1 ano \\
\hline Lízia & 24 anos & Relações Internacionais & Nenhum & 8 meses \\
\hline Lauper & 24 anos & $\begin{array}{l}\text { Superior Incompleto } \\
\text { (mas não especificou o curso) }\end{array}$ & Nenhum & 2 anos \\
\hline
\end{tabular}

Fonte: Elaborada pelas autoras, UnB, Brasília, DF, 2020

A seguir, daremos continuidade à análise das respostas dos participantes, focando em suas motivações e percepções acerca de suas atividades voluntárias e como eles percebem o voluntariado na construção de suas formações acadêmicas.

\section{As Motivações dos Voluntários no ensino de Português Língua de Acolhimento}

Quando questionados sobre os motivos e razões que os levaram a procurar e/ou iniciar uma prática voluntária voltada para o ensino de Português para imigrantes e refugiados, os participantes revelaram que possuir a experiência nesta área em específico, atuando como 
professores da língua materna, é algo que os suscitaram para o início desta prática, como é possível acompanhar na Tabela 2, com os aspectos mais relevantes em destaque:

Tabela 2. Motivação dos participantes para a prática voluntária

\begin{tabular}{|c|c|}
\hline Participante & Motivação para a prática voluntária \\
\hline Ana & "Projeto de extensão da UnB." \\
\hline Maria & "Foram vários os motivos, mas o que me impulsionou foi o amor que tenho pela educação." \\
\hline Bruno & $\begin{array}{l}\text { "Sempre quis ter essa experiência de ensinar português para estrangeiros para entender como } \\
\text { seria ensinar minha lingua materna como uma Lingua Estrangeira." }\end{array}$ \\
\hline Babel & "Conseguir experiência para transformar o PBSL na minha fonte de renda." \\
\hline Divina & "Agregar conhecimento e pelo prazer de ensinar e aprender." \\
\hline Lízia & $\begin{array}{l}\text { "Acredito que todo conhecimento deve ser compartilhado e que as práticas voluntárias são de } \\
\text { extrema importância para que haja alguma mudança. De nada adianta eu ter estudado se eu } \\
\text { não puder compartilhar o que sei para ajudar alguém - ou a sociedade como um todo." }\end{array}$ \\
\hline Lauper & $\begin{array}{l}\text { "Aplicar o conhecimento acadêmico à vida e poder ajudar as pessoas precisa ter acesso a } \\
\text { esse conhecimento." }\end{array}$ \\
\hline
\end{tabular}

Fonte: Elaborada pelas autoras, UnB, Brasília, DF, 2020

Quando Cohen (1964) nos diz que cada indivíduo tem seus motivos para se engajar em determinadas tarefas, percebe-se a subjetividade e complexidade das motivações das práticas sociais. Entretanto, identificamos que todos os participantes, nessa pesquisa, tencionam suas motivações pela busca por aprendizagem e troca de experiências.

Destacamos que o perfil destes participantes se revela como instrumental e altruísta (Salamon, 1999), uma vez que eles se encontram nesses projetos para adquirirem novas habilidades, mas ao mesmo tempo se sentem solidarizados para com as pessoas que ensinam, ou seja, há uma satisfação pessoal. Além do mais, é perceptível a preocupação de todos em relação à carreira, uma outra motivação, que segundo Clary, Snyder e Ridge (1992) impulsionam o voluntariado.

Depreendemos isso, por exemplo, na resposta da participante Ana, que explicita sua motivação em fazer parte de um curso de extensão, nos revelando essa busca por fazer parte de algo que lhe proporcione adquirir novas habilidades, ou na resposta de Babel, que vê no voluntariado uma forma de agregar ao currículo e conseguir uma renda melhor quando procurar um trabalho formal.

Os demais participantes citaram a "experiência de ensinar e aprender" como algo que os impulsionou voluntariar, sendo que esta ação está atrelada ao prazer, amor, curiosidade e oportunidade de fazer alguém progredir, nos revelando a percepção altruística dos participantes.

Desta forma, não há um motivo único que leve estes indivíduos a atuarem no voluntariado, pois há uma complementariedade em razões para que estes participantes permaneçam em suas atribuições. Percebemos que é o conjunto de motivações que unifica a prática.

\section{A Responsabilidade do Ensino da Língua materna na Prática Voluntária}

Ao abordarmos a questão da percepção desses voluntários como professores da língua portuguesa para imigrantes e refugiados, percebemos que esses indivíduos reconhecem a responsabilidade que possuem ao trabalharem com um público que necessita de um olhar diferenciado.

Identificamos que os participantes reconhecem seus papéis como mediadores desta inserção social por parte dos imigrantes e refugiados através do idioma, usando o ensino da língua numa perspectiva de acolhimento (Lopes, \& Diniz, 2018). Na Tabela 3, destacamos em negrito as respostas destes voluntários que evidenciam essa preocupação social: 
Tabela 3. Impressões e desafios do PLAc

\begin{tabular}{|c|c|}
\hline Participante & $\begin{array}{l}\text { Impressões e desafios no processo de ensinar Português Língua de Acolhimento para } \\
\text { imigrantes e refugiados }\end{array}$ \\
\hline Ana & $\begin{array}{l}\text { É um processo que requer do professor antes de tudo empatia e depois planejamento e sinto } \\
\text { dificuldade de conseguir manter um planejamento do início ao fim. A conquista de cativar esses } \\
\text { alunos como professora e manter contato com eles. }\end{array}$ \\
\hline Maria & $\begin{array}{l}\text { Eu aprendo mais que ensino. Em uma turma de } 30 / 50 \text { alunos, onde todos têm culturas diferentes, } \\
\text { nacionalidades diferentes e línguas diferentes, eles têm mais a ensina do que o prof. voluntário. } \\
\text { Me vejo apenas como mediadora, o aprendizado é compartilhado. Dificuldade é lidar com } \\
\text { alunos que não falavam nenhuma língua de mediação além da sua língua materna. }\end{array}$ \\
\hline Bruno & $\begin{array}{l}\text { Ensinar português no Brasil para estrangeiros é totalmente diferente de ensiná-lo no } \\
\text { exterior, pois envolve processos diferentes. No primeiro o aluno está em processo de imersão } \\
\text { e tem contato com a língua o tempo todo tornando o aprendizado mais rápido. No segundo, os } \\
\text { alunos têm a limitação de o português ser apenas usado em sala de aula o que proporciona menos } \\
\text { oportunidades de práticas na língua. Dificuldades tive com o ambiente de sala de aula que era } \\
\text { apertado, mal iluminado, por vezes quente, sem muita estrutura. }\end{array}$ \\
\hline Babel & $\begin{array}{l}\hat{E} \text { um processo que se modifica de acordo com a turma, nunca é um processo igual, cada aluno } \\
\text { possui suas especificidades culturais e acadêmicas. A maior dificuldade foi manter uma } \\
\text { distância entre o ensino e a vida pessoal de cada aluno, saber que o tempo que cada um demora } \\
\text { pra conseguir emprego não depende apenas de mim e conseguir me cobrar menos ao ver a } \\
\text { pessoal deles(as). Cada aluno que me falava seus avanços em relação a empregabilidade ou } \\
\text { sociabilidade em Brasília era uma conquista para mim. }\end{array}$ \\
\hline Divina & $\begin{array}{l}\text { Apesar de ser maravilhosa a experiência, sinto que poderia buscar mais didáticas em materiais } \\
\text { fora dos exigidos em sala. A dificuldade é lidar com as desigualdades de gênero e religião } \\
\text { tentar mantê-los juntos... mas com paciência, carinho e atenção conseguiremos. }\end{array}$ \\
\hline Lízia & $\begin{array}{l}\text { O processo de ensinar e aprender é multifacetado e depende de uma série de elementos. O } \\
\text { professor serve para auxiliar que o aluno acesse o conhecimento, mas o aluno precisa estar } \\
\text { aberto para buscá-lo de outras formas também e não se restringir a sala de aula. As maiores } \\
\text { dificuldades que eu analiso são referentes às questões culturais e as condiçóes para executar o } \\
\text { projeto. Por exemplo, em diversas culturas as turmas são separadas entre homens e mulheres. } \\
\text { Porém, isso não acontece no Brasil. Sempre me ocorre a dúvida se devemos separar essas } \\
\text { turmas, como é de costume dessas pessoas, ou se devemos deixar as turmas mistas como é de } \\
\text { costume na maioria dos centros de ensino brasileiros. Outra questão é que algumas pessoas } \\
\text { precisam levar seus filhos para a sala de aula. Isso é bastante complexo. }\end{array}$ \\
\hline Lauper & $\begin{array}{l}\text { Foram grandes desafios, mas preferi manter o bom ânimo e não desistir, a troca de } \\
\text { conhecimento e experiência foi muito proveitosa! Pude aplicar o conhecimento acadêmico, } \\
\text { corrigir na prática o que não funcionava e me reinventar. Dificuldades quanto a usar uma língua } \\
\text { para ser a "ponte" entre o processo de aprendizagem e o objetivo do aprendiz. }\end{array}$ \\
\hline
\end{tabular}

Fonte: Elaborada pelas autoras, UnB, Brasília, DF, 2020

Se pensamos o Português Língua de Acolhimento como a prática de ensinar a língua majoritária de um país para imigrantes e refugiados, proporcionando a ligação entre esses indivíduos e a língua alvo de forma acolhedora, oferecendo, para esse público meio para utilizar o idioma em suas ações cotidianas e sociais (Amado, 2016), então perceberemos que os voluntários participantes dessa pesquisa identificam esse conceito e o aplicam em suas atividades de cunho social.

Ao mesmo tempo, é possível identificar que os participantes possuem consciência sobre seus deveres, sobre suas atribuições dentro destes projetos, quando nos deparamos com a resposta de Ana e Maria ao dizerem que são "mediadoras" do conhecimento e que estão em sala para “auxiliarem' a aprendizagem de seus alunos.

É importante destacar que os voluntários se percebem pensando criticamente sobre suas ações, como por exemplo quando vemos a resposta de Ana ao dizer que se preocupa em "manter um planejamento" ou Babel quando reforça a ideia de que "é um processo que se modifica de acordo com a turma" ou Divina, quando reflete que necessita "buscar mais didática" para atuar com os imigrantes e refugiados, concluímos que o grupo se vê pensando 
no social e humano (Penner, 2002) e que há uma preocupação não só com o que fazem, mas também com o público que trabalham.

Entretanto, essas ações coletivas envolvem um elevado grau de complexidade, como já explicitado por Cohen (1964), quando eles não sabem o que fazer com o sentimento de responsabilidade para com seus alunos e percebemos isso nas respostas de Babel, que reflete sobre como "manter a distância entre o ensino e a vida pessoal de cada aluno" e nas respostas de Divina e Lízia que se indagam sobre como lidar com "as desigualdades de gênero e religião" em sala de aula. Todas essas falas são importantes, pois revelam a responsabilidade social que estes voluntários possuem.

Ademais, identificamos nas falas acima uma preocupação em amenizar conflitos linguísticos e socias, além da procura em estabelecer condições necessárias para o ensino do idioma (Barbosa, \& São Bernardo, 2017), ao notarmos que os professores voluntários se dedicam aos planejamentos, à produção de material didático e estudos paralelos para um melhor desempenho em sala de aula.

\section{O Impacto do Voluntariado na Formação Profissional e Pessoal}

O voluntariado contribui para um senso de solidariedade entre os indivíduos que atuam juntos em causas sociais (Penner, 2002). Quando questionamos os participantes desta pesquisa sobre a relevância das ações sociais sem fins lucrativos nas quais estavam engajados, percebemos que os mesmos reconheceram o valor imaterial que esta prática oferece.

$\mathrm{O}$ enriquecimento profissional e acadêmico se mostrou forte nas respostas dos voluntários. Ademais, emoções como empatia, gratidão, positividade, paciência e respeito também são percebidas como uma forma de reflexão por parte dos participantes, como é possível acompanhar na Tabela 4.

Tabela 4. A importância do trabalho voluntário

\begin{tabular}{|c|c|}
\hline Participantes & Importância do voluntariado \\
\hline Ana & $\begin{array}{l}\text { É de grande importância pois essas aulas de português só existem, ainda, nessa modalidade. } \\
\text { Me trouxe enriquecimento profissional no sentido de me desafiar todos os sábados a lidar } \\
\text { com emoções e singularidades transparentes me tornando uma pessoa muito mais empática. }\end{array}$ \\
\hline Maria & $\begin{array}{l}\text { É extremamente importante. Em um país como o Brasil que não dar conta de toda as demandas } \\
\text { sociais, o voluntariado organiza o caos. Ensinar e aprender é muito mais que um salário no } \\
\text { final do mês, hoje com certeza sou mais humana e mais sensível. E carrego comigo a certeza } \\
\text { de que professor não é o salvador do mundo, nem tem que se ver como tal, mas tem um papel } \\
\text { fundamental na vida dos seus alunos. }\end{array}$ \\
\hline Bruno & $\begin{array}{l}\text { Na falta de políticas públicas para a tomada de decisões e execução de ações para ajudar } \\
\text { pessoas socialmente desprivilegiadas como o caso dos imigrantes e refugiados, é } \\
\text { necessária a mobilização de voluntários que tenham sensibilidade pela causa e queiram } \\
\text { transformar a realidade dessas pessoas marginalizadas pela sociedade que sonham em ter } \\
\text { melhores condições de vida. Tenho orgulho de ter essa experiência gravada no meu } \\
\text { currículo. Contudo, até o momento não a usei como vantagem profissional para conseguir } \\
\text { um emprego. }\end{array}$ \\
\hline Babel & $\begin{array}{l}\text { O trabalho voluntário é muito importante para suprir a ineficiência do estado. No mais, } \\
\text { acredito que todos os trabalhos deveriam ser remunerados, muitas pessoas querem ajudar e } \\
\text { não possuem suporte financeiro. Em uma realidade em que a maioria dos voluntários são } \\
\text { alunos de graduação ou mestrado, estes passam no mínimo metade do seu dia voltados para } \\
\text { responsabilidades acadêmicas. A experiência de um trabalho multicultural afeta diariamente } \\
\text { e positivamente minha visão de mundo e o olhar que tenho sobre estruturas sociais. }\end{array}$ \\
\hline Divina & $\begin{array}{l}\text { Importantíssimo para a inclusão social e linguística dos estrangeiros que procuram refúgio } \\
\text { no Brasil. Essa inclusão e Acolhimento são primordiais para a vivência dos estrangeiros aqui } \\
\text { no Brasil. Abriu uma visão de que posso ajudar a mudar a vivência dos estrangeiros aqui no } \\
\text { Brasil de modo positivo. Isso é gratificante além de ser uma troca de experiências únicas e } \\
\text { inesquecíveis. }\end{array}$ \\
\hline
\end{tabular}




\begin{tabular}{|l|l|}
\hline Lízia & $\begin{array}{l}\text { É internamente e externamente importante. Se envolver com trabalho voluntário te ajuda a } \\
\text { pensar de maneira diferente sobre a vida, além de ajudar a minimizar os problemas sociais. } \\
\text { Ainda não teve impacto na minha vida profissional, apenas na minha vida pessoal. Eu pude } \\
\text { facilitar que várias pessoas próximas entendessem sobre refúgio, migrações, problemas } \\
\text { sociais e ajudar várias pessoas no processo de (re)integração em uma sociedade, a partir do } \\
\text { idioma. }\end{array}$ \\
\hline Lauper & $\begin{array}{l}\text { É importante poder ajudar quem não tem condições de pagar ou ter acesso fácil a qualquer } \\
\text { tipo de serviço que tenha necessidade. E fazer o bem. Passei a ser mais grata por tudo o que } \\
\text { é tenho, ser mais empática e ter mais paciência com as pessoas. }\end{array}$ \\
\hline
\end{tabular}

Fonte: Elaborada pelas autoras, UnB, Brasília, DF, 2020

A partir das respostas dos participantes, constatamos a importância que esta modalidade de ensino representa aos mesmos como forma de contribuição social. Não há, até este momento, a oferta de Português Língua de Acolhimento pelo Estado, sendo que docências voluntárias, como estas abordadas neste artigo, buscam suprir esta lacuna de assistência social (Lopes, \& Diniz, 2018).

Destacamos que os participantes sentem essa "falta" de apoio do Governo e citam isso em suas respostas. Percebemos isso na fala de Maria, que enfatiza sua opinião de que "o Brasil não dá conta de todas as demandas sociais", ou Bruno, ao dizer que há a "falta de políticas públicas para a tomada de decisões e execução de ações para ajudar as pessoas" e Babel, ao explicitar que "o trabalho voluntário é muito importante para suprir a ineficiência do Estado".

Notamos essa insatisfação por parte dos voluntários com o Estado, entretanto, devemos entender que essa responsabilidade para com o meio social deve ser entendido como algo coletivo, que se desenvolve a partir das ações tanto da sociedade civil quanto do Estado, sendo que ambos devem "possuir o mesmo interesse e unirem esforços para atingirem os mesmos objetivos sociais" (Camargos, 2008, p. 67).

Outro aspecto que destacamos nas respostas do grupo foi sobre a necessidade de se pensar em remunerar essa ação social. Para o participante Babel "todos os trabalhos deveriam ser remunerados, pois muitas pessoas querem ajudar e não possuem suporte financeiro". No artigo 1 da lei do voluntario (Brasil, 1998) temos a definição de trabalho voluntário como sendo toda ação social não remunerada. No mesmo artigo, há a afirmação de que existe a possibilidade de haver uma ajuda de custos para quem atua em projetos sociais, mas isso vai depender de cada instituição.

Mesmo não recebendo um valor monetário pelo trabalho que desenvolvem, os participantes desta pesquisa se sentem recompensados em suas ações, e identificamos isso nas respostas de Ana, que diz ter recebido "enriquecimento profissional", ou na resposta de resposta de Maria, que aborda o fato de que para ela "ensinar e aprender é muito mais do que um salário no final do mês".

Identificamos então, essas "recompensas simbólicas" (Cnaan, \& Cascio, 1988, p. 35), que nos fazem pensar no voluntariado como algo que necessita de comprometimento e desempenho, além do fato de que essas ações trarão consequências pessoais e profissionais de valor tangível e intangível para os participantes, como identificamos na resposta de Bruno ao falar que tem "orgulho de ter essa experiência gravada no currículo" ou na resposta de Lauper, que diz ter "passado a ser mais grata por tudo o que eu tenho, ser mais empática e ter mais paciência com as pessoas".

Assim a importância está não só na ação de ensinar, mas em todo o aprendizado obtido a partir de tal prática docente. E como percebemos nas respostas dos participantes, o que o ensino voluntário de PLAc possibilita aos mesmos vai muito além do que um trabalho remunerado poderia oferecer. 


\section{CONSIDERAÇÕES FINAIS}

A identidade do agente voluntário é entendida pela forma como o indivíduo se identifica em suas ações. Segundo Lopes (2006) as pessoas tendem a se comprometer com algo quando se veem representadas e/ou com a possibilidade de transformação em seus comportamentos sociais. Em nossa pesquisa, verificamos que os voluntários que atuam como o ensino de Português Língua de Acolhimento reconhecem suas ações do ponto de vista instrumental e altruísta.

Para estes voluntários, estas práticas de ensino possibilitam mais do que a troca de experiências e desenvolvimento de habilidades, pois mesmo que eles estejam motivados a agirem objetivando uma melhor formação profissional e acadêmica, o "fazer o bem" se conecta com o acolhimento linguístico e social que estão desenvolvendo.

Destacamos a atenção que os participantes deram ao fato de o Estado não contribuir de forma efetiva na promoção de políticas públicas e demandas sociais, cabendo ao voluntário, e em específico nesta pesquisa para a docência voluntária, o papel de suprir uma necessidade que deveria ser solucionada pelo Estado. Há uma insatisfação e há a procura por um apoio institucional e financeiro, que faça com que sociedade civil e o poder público atuem juntos socialmente.

Acrescentamos ainda o fato de os participantes dessa pesquisa trazerem para discussão a necessidade de se pensar a remuneração dessas práticas sociais, como um pequeno auxílio ou uma forma de facilitar o trabalho voluntário. Existem instituições que ajudam os voluntários com bolsas ou adicionais que cubram o custo da locomoção, alimentação ou compra de materiais, mas estas são exceções. No caso de nossos pesquisados, nenhum recebe bolsa ou auxílio financeiro para trabalhar e muitos tiram do próprio bolso para desenvolverem suas atividades em sala. Assim, ficamos com a reflexão: por que o trabalho voluntário não deve ser remunerado?

Desta forma, finalizamos esta pesquisa constatamos a efetiva relação entre estes projetos sociais e a formação pessoal e profissional dos participantes desta pesquisa. Ao se identificarem como professores voluntários de Português para imigrantes e refugiados, estes indivíduos se sentem mais engajados em se desenvolverem como seres humanos e promoverem uma rede contínua de construção social.

\section{NOTAS}

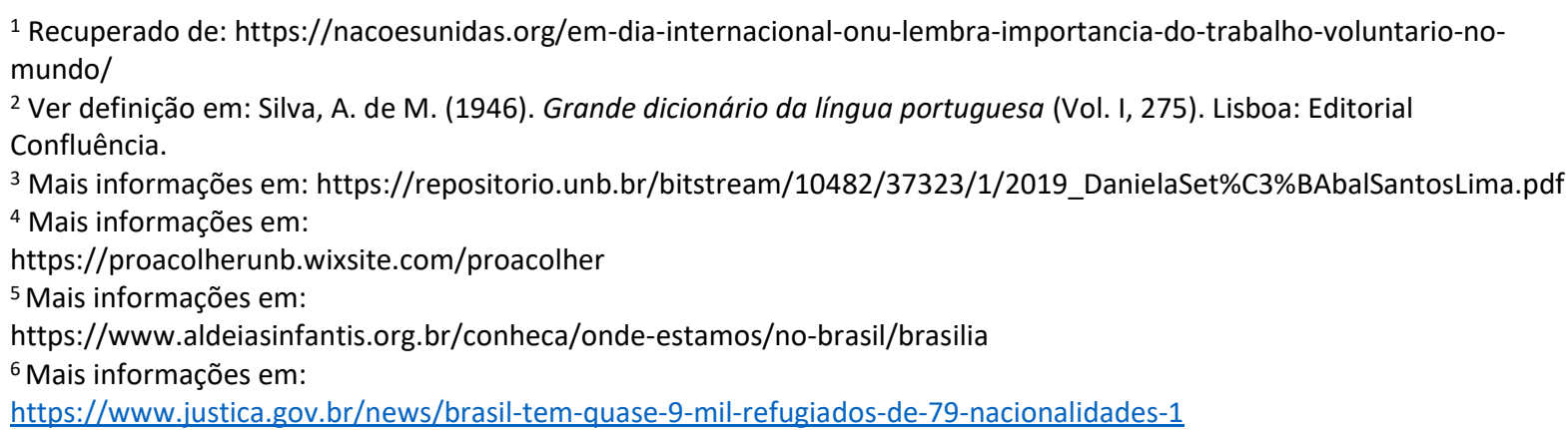

\section{REFERÊNCIAS}

Amado, R. de S. (2016). O ensino de português para refugiados: Caminho para a cidadania. Em R. L. Sá (Org.), Português para falantes de outras línguas: Interculturalidade, inclusão social e políticas linguísticas (Vol. 1, 69-86). Campinas, SP: Pontes.

Ançã, M. H. (2006). Língua portuguesa e imigração: Entre língua de acolhimento e língua de afastamento. Atas do XIII ENDIPE/Encontro Nacional de Didática e Prática de Ensino (s/pp., versão em CD-ROM), Recife, Brasil.

Anheier, K. H., \& Salamon, L. M. (1999). Volunteering in cross-national perspective: Initial comparisons, law and contemporary problems. Law and Contemporary problems, 62 (4), 43-65. 
Barbosa, L. M. de A., \& São Bernardo, M. de. (2017). Língua de Acolhimento. Em L. Cavalcanti, T. Botega, D. Araújo, \& T. Tonhati (Eds.), Dicionário crítico de migrações internacionais (434-437). Brasília, DF: Universidade de Brasília.

Brasil. (1998). Lei n ${ }^{\circ} 9.608$ de 18, de fevereiro de 1998. Dispõe sobre o serviço voluntário e dá outras providências. Brasília, DF: Diário Oficial da República Federativa do Brasil. Recuperado de: http://www.planalto.gov.br/ccivil_03/leis/19608.htm.

Burrel, G., \& Morgan, G. (1979). Sociological paradigms and organizational analysis: Elements of the sociology of corporate life. London: Heinemann.

Camargos, A. A. M. (2008). Direito do trabalho no terceiro setor. São Paulo: Saraiva.

Clary, E. G., Snyder, M., \& Ridge, R. D. (1992). Volunteers' motivations: a functional strategy for the recruitment, placement and retention of volunteers. Nonprofit Management and Leadership, 2 (4), 333-350.

Cnaan, A. R., \& Cascio, T. (1998). Performance and commitment: Issues in management of volunteers in human service organizations. Journal of Social Service Research, 24, 1-37.

Cohen, N. E. (1964). O papel do voluntário na sociedade moderna. Rio de Janeiro: Fundo de Cultura.

Lopes, A. (2006). Trabalho voluntário e envelhecimento: Um estudo comparativo entre idosos americanos e brasileiros. (Tese de Doutorado, Universidade Estadual de Campinas, Campinas, São Paulo, Brasil).

Lopez, A. P. de A., \& Diniz, L. R. A. (no prelo). Iniciativas jurídicas e acadêmicas brasileiras para o acolhimento de imigrantes deslocados forçados.

Morgan, G., Frost, P., \& Pondy, L. (1983). Organizational symbolism. Em L. R. Pondy, R. J. Frost, G. Morgan, \& T. C. Dandridge (Eds.). Organizational symbolism (3-35). Connecticut: Jay Press.

Penner, L. A. (2002). Dispositional and organizational influences on sustained volunteerism: An interactionist perspective. Journal of Social Issues, 58 (3), 447-467.

Rey, F. G. (2005). Pesquisa qualitativa e subjetividade: Os processos de construção da informação. São Paulo: Thomson.

SESC. DN. DPD. GEP. (2007). Manual de procedimentos e gestão do voluntariado: Mesa Brasil SESC. Rio de Janeiro: SESC, Departamento Nacional. 